\title{
Relações entre agricultura orgânica e agroecologia: desafios atuais em torno dos princípios da agroecologia*
}

\section{Relations Between Organic Agriculture and Agroecology: Current Challenges Around the Principles of Agroecology}

\author{
Lucimar Santiago ABREU** \\ Stéphane BELLON*** \\ Alfio BRANDENBURG ${ }^{* * * *}$ \\ Guillame OLLIVIER ${ }^{* * * * *}$ \\ Claire LAMINE ${ }^{* * * * * *}$ \\ Moacir Roberto DAROLT* \\ Pascal AVENTURIER ${ }^{* * * * * * * *}$
}

\begin{abstract}
RESUMO
Neste artigo, exploramos a relação entre Agroecologia e Agricultura Orgânica. O debate na comunidade científica em alguns países e a análise das posições ou discursos de pesquisadores e artigos apontam para distintas combinações, trocas e interações entre a Agricultura Orgânica e Agroecologia. Nesse sentido, primeiramente, com base na revisão de literatura, mostramos distintas interações entre esses estilos de agricultura. Além disto, analisamos as controvérsias das agriculturas em foco, bem como apresentamos uma síntese de dois estudos de caso para ilustrar a aplicação prática de princípios da agroecologia, avaliando práticas e valores éticos, relacionando-as com as lógicas familiares ou patronais de funcionamento da produção. Concluímos que as relações entre os estilos de agricultura não podem ser reduzidas a uma simples oposição entre um campo científico e um domínio prático. Diversos elementos devem ser tomados em conta, entre os quais o grau de integração sociocultural (valores) à sociedade, as práticas e a inserção no mercado. Estudos no território brasileiro exemplificam a diversidade de relações existentes, seja inclusiva ou exclusiva, observando-se uma fluidez entre conceitos de agroecologia e agricultura orgânica.
\end{abstract}

Palavras-chave: agricultura orgânica; agroecologia; transição agroecológica.

\footnotetext{
"Este texto é resultante do intercâmbio entre pesquisadores e estudantes que participam do Projeto "Agroecologia na França e no Brasil: entre redes científicas, movimentos sociais e políticas publicas", que sustenta o acordo CAPES/COFECUB 716/2011.

** Doutora em Ciências Sociais (UNICAMP). Pesquisadora da Empresa Brasileira de Pesquisa Agropecuária - Embrapa Meio Ambiente, Jaguariúna, Brasil. E-mail: lucimar.abreu@embrapa.br

"** Engenheiro em Agronomia (Agroparistech). Pesquisador da UR 0767, Unidade de Ecodesenvolvimento do INRA, Avignon, França. E-mail: bellon@avignon.inra.fr

**** Doutor em Ciências Sociais (UNICAMP). Professor do Departamento de Ciências Sociais da Universidade Federal do Paraná (UFPR). E-mail: alfio@onda.com.br

****** Engenheiro em Sociologia (Universidade de Paris X, Nanterre). Pesquisador da UR 0767, Unidade de Ecodesenvolvimento do INRA, Avignon, França. E-mail: gollivier@avignon.inra.fr

${ }^{* * * * * * * *}$ Doutora em Sociologia (EHESS). Pesquisadora da UR 0767, Unidade de Ecodesenvolvimento do INRA, Avignon, França. E-mail: claire.lamine@avignon.inra.fr ******** Doutor em Meio Ambiente e Desenvolvimento (UFPR). Profissional de Ciência e Tecnologia no Instituto Agronômico do Paraná (IAPAR). E-mail: moadarolt@gmail.com

********** Mestre em Ciência da Informação (Universidade de Grenoble). Engenheiro do INRA, Avignon, França. E-mail: Pascal.Aventurier@avignon.inra.fr
} 


\begin{abstract}
In this article we explore the relationship between Agro-ecology and Organic Agriculture. The debate within scientific communities in different parts of the world and the analysis of positions or discourses of researchers and articles indicate that different combinations, exchanges and interactions between Organic Agriculture and Agro-ecology are underway. In this regard, and initially based on review of the literature, we look at the ongoing interaction between these two styles of agricultural practices. We then move on to analyze emerging controversies and present a synthesis of two case studies which illustrate the practical applications of agro-ecological principles, evaluating practices and ethical values and relating them to familial or entrepreneurial logics of production. We conclude that the relations between agricultural styles cannot be reduced to a simple opposition between a scientific field and a practical domain. A variety of elements must be taken into account, amongst which we emphasize the degree of socio-cultural integration (values) to society, practices and market participation. Studies within Brazil provide evidence of the diversity of current relationships, whether inclusive or exclusive, and of the fluidity marking concepts of agro-ecology and organic agriculture.
\end{abstract}

Keywords: organic agriculture; agro-ecology; agroecological transition.

\section{Introdução}

Apesar de o modelo agrícola convencional ou industrial ter proporcionado aumentos significativos de produtividade dos cultivos e formado sistemas "aparentemente" rentáveis, tem sido severamente questionado por estar associado a uma série de problemas ecológicos e socioambientais. Entre os mais relevantes, situam-se a dependência crescente de combustíveis fósseis e a baixa eficiência energética; a degradação dos recursos naturais, contaminação de alimentos e meio ambiente; o uso crescente de agrotóxicos (inseticidas, herbicidas, fungicidas) e fertilizantes químicos; o impacto negativo sobre a saúde dos agricultores e dos consumidores; a erosão genética (perda de variedades crioulas); diminuição da biodiversidade com a simplificação dos agroecossistemas; a perda de técnicas, da cultura e de saberes tradicionais dos agricultores; e, finalmente, o aumento do êxodo e da pobreza rural (SARANDON, 2009).

Embora esses problemas venham se manifestando desde a modernização intensiva na agricultura, apenas recentemente as crises ambiental, alimentar, econômica, climática e social têm se mostrado como face de uma mesma moeda e imposto uma mudança urgente na forma de pensar, atuar e pesquisar. Será preciso uma mudança do pensamento simplista para um pensamento complexo que permita enfrentar o desafio ambiental (LEFF, 2008).

As agriculturas tidas como alternativas ao modelo convencional são consideradas como de potencial para contribuir e enfrentar esses desafios. Entre elas estão aquelas relacionadas à segurança alimentar e à preservação do meio ambiente, tais como a Agroecologia (AE) e a Agricultura Orgânica (AO). Para além de objetivos comuns, ambas $(\mathrm{AE})$ e $(\mathrm{AO})$ se referem à ecologia $\mathrm{e}$ questionam o modelo tecnológico implantado durante o século XX; sustentam-se em definições, paradigmas, princípios diferenciados, conforme Quadro 1. O quadro permite estabelecer comparações e favorece a análise mediante um conjunto de parâmetros. Trata de elementos que possibilitam efetuar a identificação dos dois estilos de agricultura e apresentar as suas características resumidamente. Todavia, vale lembrar que o esquema representa uma simplificação, visto que cada experiência é sempre singular. A organização do quadro é inspirada no artigo apresentado no Congresso da Sociedade Internacional de Pesquisa na Agricultura Orgânica (ISOFAR) em 2011 (BELLON et al., 2011).

Conforme pode ser observado no Quadro 1, as agriculturas em análise têm seus fundamentos em paradigmas distintos. Enquanto a Agricultura Orgânica tem suas raízes na ciência do solo, a Agroecologia sustenta seus princípios na ecologia. AAgroecologia privilegia, num primeiro momento, as dimensões agronômica e ecológica (ALTIERI, 1989; GLIESSMAN, 1990) e, em seguida, as dimensões sociológica e política (GUZMÁN CASADO et al., 2000). Esses autores defendem a visão de que a $\mathrm{AE}$ representa um novo campo de conhecimento de apoio ao processo de transição em direção à sus- 
QUADRO 1 - MODELOS DE AGRICULTURA ORGÂNICA (AO) E AGROECOLOGIA (AE)

\begin{tabular}{|c|c|c|}
\hline & AO & $\mathbf{A E}$ \\
\hline Paradigmas & Princípios da IFOAM - Paradigma ciências do solo & Conceitos científicos, da entomologia e da ecologia \\
\hline Definição & $\begin{array}{l}\text { Sistema geral de gestão agrícola e de produção } \\
\text { de alimentos que combina as melhores práticas } \\
\text { ambientais e um elevado nível de biodiversidade. } \\
\text { <http://eur-lex.europa.eu/LexUriServ/LexUriServ. do } \\
\text { ?uri=OJ:L:2007:189:0001:0023:ES:PDF>. }\end{array}$ & $\begin{array}{l}\text { Estudo interdisciplinar e redesenho de sistemas } \\
\text { agrícolas e agro alimentares }\end{array}$ \\
\hline Princípios & $\begin{array}{l}\text { IFOAM (2005) } \\
\text { Equidade } \\
\text { Saúde } \\
\text { Ecologia } \\
\text { Justiça }\end{array}$ & $\begin{array}{l}\text { GLIESSMAN (1999) } \\
\text { (i) baixa dependência de inputs externos; } \\
\text { (ii) uso de recursos naturais renováveis; } \\
\text { (iii) mínimo de impacto adverso ao meio ambiente; } \\
\text { (iv) manutenção da capacidade produtiva; } \\
\text { Diversidade biológica e cultural; } \\
\text { (iv) conhecimento da população local; } \\
\text { v) satisfação das necessidades humanas }\end{array}$ \\
\hline $\begin{array}{l}\text { Conceitos de } \\
\text { referências }\end{array}$ & Sistemas de produção; cadeias de valores. & Agroecossistemas e soberania alimentar \\
\hline Atores-chave & Produtores, consumidores, processos e certificadores. & $\begin{array}{l}\text { Diversidade de produtores familiares e a relação } \\
\text { com consumidores }\end{array}$ \\
\hline $\begin{array}{l}\text { Modelos de } \\
\text { referências }\end{array}$ & $\begin{array}{l}\text { Sistemas integrados de policultivo e gado; } \\
\text { horticultura periurbana; Biodinâmica, Orgânica, } \\
\text { Ecológica }\end{array}$ & $\begin{array}{l}\text { Sistemas tradicionais multiestratificados. Iniciativas } \\
\text { de sistematização de experiências contemporâneas }\end{array}$ \\
\hline $\begin{array}{l}\text { Perspectiva de } \\
\text { mudança }\end{array}$ & $\begin{array}{l}\text { Focaliza a conversão dos produtores e suas redes } \\
\text { profissionais de proximidade }\end{array}$ & $\begin{array}{l}\text { Focaliza sobre os níveis de transição (ERS) e sua } \\
\text { inserção em sistemas agroalimentares }\end{array}$ \\
\hline Tecnologias & $\begin{array}{l}\text { Uso de substâncias naturais e o não uso de } \\
\text { transgênicos. Aceita se o uso de adubos químicos } \\
\text { durante o período de conversão }\end{array}$ & $\begin{array}{l}\text { Valorização dos ciclos de nutrientes, práticas de } \\
\text { proteção vegetal e possibilidades de uso de adubos } \\
\text { químicos durante o período de conversão }\end{array}$ \\
\hline $\begin{array}{l}\text { Biodiversi- } \\
\text { dade }\end{array}$ & $\begin{array}{l}\text { Impacto orientado (efeito das práticas sobre } \\
\text { biodiversidade) }\end{array}$ & $\begin{array}{l}\text { Recursos orientados (valorização da biodiversidade } \\
\text { como fator da produção) }\end{array}$ \\
\hline Alimentação & Qualidade dos produtos, saúde dos consumidores & Sistemas agroalimentares e soberania alimentar \\
\hline $\begin{array}{l}\text { Normas de } \\
\text { produção }\end{array}$ & $\begin{array}{l}\text { Regras de produção aceitas internacionalmente e } \\
\text { nacionalmente }\end{array}$ & Sem padrão internacional, regras aceitas localmente \\
\hline Certificação & \begin{tabular}{|l}
$\begin{array}{l}\text { Predomínio da Certificação por Terceira Parte } \\
\text { (auditoria) atestada com selos }\end{array}$ \\
\end{tabular} & $\begin{array}{l}\text { Sistemas de garantia participativos, vendas diretas } \\
\text { com controle social }\end{array}$ \\
\hline
\end{tabular}

FONTE: BELLON, S. et al., 2011

tentabilidade. Nesse sentido, a Agroecologia entendida como um estilo de agricultura pode ser mais ou menos sustentável quando é capaz de atender, de maneira integrada, aos seguintes princípios (REIJNTJES et al., 1992; GLIESSMAN, 2009): a) baixa dependência de inputs externos e reciclagem interna; b) uso de recursos naturais renováveis localmente; c) mínimo de impacto adverso ao meio ambiente; d) manutenção em longo prazo da capacidade produtiva; e) preservação da diversidade biológica e cultural; f) utilização do conhecimento e da 
cultura da população local; g) satisfação das necessidades humanas de alimentos e renda.

Por outro lado, a Agricultura Orgânica sustenta-se, segundo a IFOAM (2005), em princípios de equidade, saúde e justiça e em paradigmas da ciência do solo. É entendida por autores de forma crítica, centrada numa visão minimalista, na medida em que ela é vista como substituição simples de insumos, em detrimento do redesenho dos sistemas agrícolas, e praticada segundo a lógica organizacional da moderna agricultura convencional. Apesar dessas críticas, a conversão para a agricultura orgânica é frequentemente lembrada por esses autores para ilustrar as perspectivas de transição agroecologica, como se verá mais adiante.

A abordagem da Agroecologia definida por Altieri (1995) salienta a importância do redesenho como princípio fundamental, além da agrobiodiversidade, apontando quatro componentes básicos de um agroecossistema sustentável: (1) o uso da cobertura vegetal; (2) fornecimento regular de matéria orgânica no solo para promover atividades bióticas; (3) os mecanismos associados ao ciclo de nutrientes tais como as rotações, agricultura integrada (consórcio) e o uso de leguminosas, e (4) regulação de pragas através de controle biológico e da biodiversidade e de inimigos naturais (OELOFSE et al., 2011).

Mas, se por um lado a AE é tratada como um novo enfoque científico de estudos dos agroecossistemas, identificam-se três interpretações principais da $\mathrm{AE}$, que não são exclusivas, mas complementares: como campo científico, como movimento social e como prática agrícola (WEZEL et al., 2009). Da mesma forma, a diversidade também existe dentro da $\mathrm{AO}$, não podendo ser resumida a um conjunto de práticas certificadas (SYLVANDER et al., 2006).

Sob o ponto de vista da prática agrícola, onde os agricultores assumem uma atitude pragmática, as noções de Agricultura Orgânica e Agroecologia muitas vezes se confundem. Assim, um estudo realizado por Abreu et al. (2009) identificou 156 organizações sociais que reivindicam no Brasil a denominação da Agroecologia ou da Agricultura "Orgânica", cujas inter-relações devem ser esclarecidas. Há também interpretações políticas da agricultura orgânica (BYÉ et al., 2002) e da agroecologia (BRANDENBURG, 2011), especialmente com o foco atual em matéria de certificação, relacionando frequentemente a $\mathrm{AO}$ à certificação por "auditoria" e a AE à certificação "participativa" (REBELATTO DOS SANTOS, 2005), também incorporada na França (VAN DEN AKKER, 2009).

Constatadas diferenças que resumidamente demarcam os campos da Agroecolgia e da Agricultura Orgânica e alguns questionamentos relacionados com esses campos, pretendemos contribuir com a análise das relações entre $\mathrm{AO}$ e $\mathrm{AE}$ e sugerir diretrizes para programas de investigação e desenvolvimento.

Nossa análise começa com a identificação da extensão da $\mathrm{AE}$ em várias áreas do conhecimento, com base em revisões da literatura, sobretudo no campo das ciências agronômicas e sociais. Na sequência, abordaremos as controvérsias entre $\mathrm{AO}$ e $\mathrm{AE}$, seguido pela apresentação de elementos de um estudo de caso, realizado em Itápolis, no Estado de São Paulo, e em Curitiba, no Estado do Paraná.

\section{Metodologias da pesquisa}

Esse artigo é fruto de uma análise realizada tendo em conta a perspectiva cruzada de duas disciplinas sociologia e agronomia - cuja característica marcante é a abordagem multidisciplinar e interdisciplinar desta problemática.

A pesquisa combina duas técnicas de análise: (i) a análise cienciométrica baseada em Web of Science. Neste estudo, mobilizamos os resultados das análises de cocitações exploratórias que permitem destacar as especializações internas das áreas de conhecimento (ver metodologia detalhada em OLLIVIER et al., 2011. Destaca-se que essa análise não é completa, ela é restrita à literatura publicada em revistas indexadas e selecionadas pela Web of Science, onde predomina a literatura europeia, que, no entanto, se inspira em perspectivas teóricas de origem latino-americana; (ii) estudos de caso, realizados em Itápolis (SP) (ALMEIDA; ABREU, 2009) e em Curitiba (PR) (DAROLT; CONSTANTY, 2008).

No plano sociológico, partimos da noção de campo de Bourdieu (2008) e a redefinimos à luz das questões e contextos específicos do estudo. O autor indica que o campo científico se caracteriza por disputas entre grupos que buscam ora demarcarem posicionamentos e se dife- 
renciarem em relação aos princípios e às propriedades pertinentes, eficientes e apropriadas para a produção de conhecimentos, ora se interagem para influenciar a proposição de políticas públicas (ABREU et al., 2011). A fim de compreender a complexidade do processo de decomposição e recomposição dos universos da $\mathrm{AO}$ e da AE buscamos, sem esgotar o assunto, identificar os interesses sociais e as relações de força em jogo captados através da aplicação mais ou menos importante destes princípios. Tal abordagem orienta o sentido da análise.

\section{Bases intelectuais da $A O$ e $A E$ e suas interações}

A revisão da literatura mostra que a agroecologia influencia o campo das agriculturas de base ecológica, sobretudo a partir da década de 1980 e mais fortemente a partir do novo século. O debate na comunidade científica no Brasil e em alguns países, a análise das posições ou discursos de pesquisadores e artigos também apontam para distintas combinações, trocas e interações entre a agricultura orgânica e a agroecologia.
A Figura 1 apresenta os números de publicações em AE e AO em Web of Sciences, entre os anos de 1975 e 2011, e mostra o rápido crescimento no número de publicações relacionadas à $\mathrm{AE}$ a partir de 2004, após um período bastante estável. Apesar desse crescimento recente, o corpus ainda é limitado em AE (cerca de 370 referências) em comparação com $\mathrm{AO}$ (pelo menos 15 vezes maior). A literatura predominantemente inglesa de ambas representa $15 \%$ da literatura total, sendo que $1 \%$ refere se à literatura em AE. Títulos, autores, instituições, resumos e palavras-chave da Web of Science que mencionam ao mesmo tempo AO e AE são pouco numerosos, mas estão em progressão (observe a legenda dos histogramas sobre a parte da direita da figura). Constata-se um referencial comum cruzando a $\mathrm{AO}$ e a $\mathrm{AE}$, sem diferenciar o que é dominante dentro do texto ( $\mathrm{AO}$ ou $\mathrm{AE}$ ) e como elas são entendidas. A AO e a AE surgem de tradições científicas específicas (Quadro 1), expressando particularidades temáticas importantes, como explícitaremos a seguir. Os trabalhos citados e as referências utilizadas constituem a base intelectual da $\mathrm{AO}$ e da $\mathrm{AE}$ e é esse conhecimento que dá origem e fundamenta as especialidades desses dois domínios do conhecimento (OLLIVIER et al., 2011).

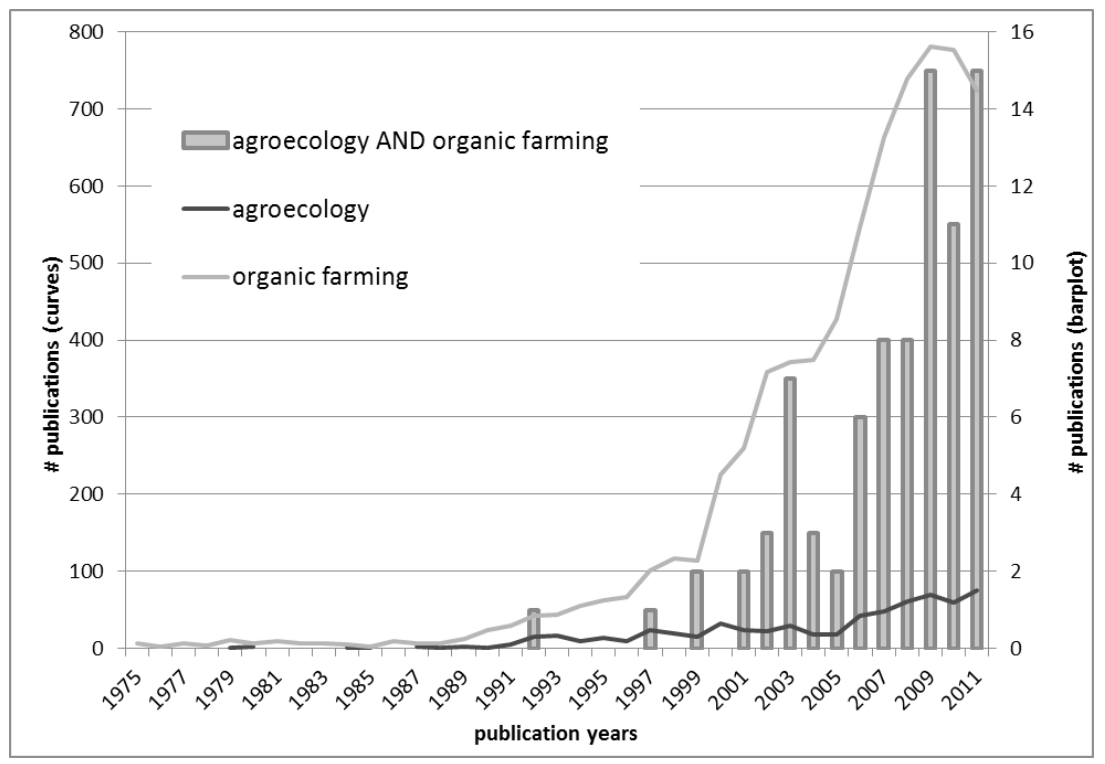

FIGURA 1 - Publicações em agroecologia (agroecology) e agricultura orgânica (organic farming) no Web of Sciences.

Fonte: OLLIVIER et al. (2011). 
No conteúdo destes domínios, observa-se que a temática da biodiversidade é importante tanto para $\mathrm{AO}$ quanto para $\mathrm{AE}$, assim como a proteção das culturas, a gestão sustentável dos solos, a pesquisa participativa e a interdisciplinaridade. Entretanto, percebe-se que temas ligados à produção familiar e à questão da soberania alimentar têm tido destaque na literatura da AE.

A produção científica em AO tal qual ela é identificada pela $W o S$, isto é, com uma orientação internacional e anglófona, surge em meados da década de 1970, no contexto da crise energética. Concentra-se primeiramente sobre a avaliação comparativa e de multicritérios de sistemas de produção (PIMENTEL et al., 1973; LOCKERETZ et al., 1981). Atualmente, neste tipo de trabalho foram adicionados novos critérios para avaliar o desempenho dos sistemas, em relação ao estoque de carbono e gás de efeito estufa. Esse é, por exemplo, o caso das abordagens dadas aos estudos do solo. Mesmo estando presentes na AO, tornaram-se referências essenciais, desde o fim dos anos de 1990.

O "paradigma edáfico" surge de fato como base dos trabalhos metodológicos, medição da biomassa e da fertilidade do solo (VANCE et al., 1987) e, portanto, tornou-se uma parte importante da avaliação dos sistemas de produção.

Estudos específicos em AO aparecem no final dos anos 1970, dando ênfase às performances da AO comparativamente à agricultura convencional (rendimento, consumo de energia, resultados econômicos) e mais recentemente destacam-se os estudos relacionados à qualidade alimentar. Observa-se um número expressivo de pesquisas e avaliações de natureza comparativa entre alimentos orgânicos e convencionais (WOESE et al., 1997; BOURN; PRESCOTT, 2002), assim como estudos sobre os determinantes do consumo de produtos orgânicos (SCHIFFERSTEIN; OUDE OPHUIS, 1998; MAGNUSSON et al., 2003).

A AE também adota posturas que são específicas. Primeiro, ela se distingue pela sua ambição inicialmente disciplinar e, em seguida, interdisciplinar (BUTTEL, 2003; DALGAARD et al., 2003). Centra-se na definição do paradigma da ecologia de agroecossistemas, baseado no trabalho de Odum (ODUM, 1969; ODUM; BARRETT, 2005). No final dos anos 1980, pode-se notar que o conceito de agroecossistema é central na perspectiva da $\mathrm{AE}$, assim como as pesquisas em $\mathrm{AO}$ focalizam os sistemas agrícolas (OLLIVIER et al., 2011) com a emergência de pesquisas denominadas sistemas de produção ("farming systems", em inglês). Também na década de 1980, os agroecólogos definem os princípios constitutivos de uma disciplina própria para estudar a produção agrícola (ALTIERI, 1987) e suas capacidades de transformação (questões do redesenho e de transição) Esta definição da AE, em seguida, foi ampliada para o conjunto dos sistemas agroalimentares (FRANCIS et al., 2003).

A ambição disciplinar se apoia principalmente sobre os trabalhos de agroecologia em contextos geográficos associados à agricultura tradicional, principalmente nos países sul-americanos, enquanto que a AO surge principalmente em contextos de ambientes temperados americanos e europeus (origem principal dos fundadores e da produção acadêmica).

A análise documental e a cocitação permitem apontar a variedade de temas abordados pela AE. Eles podem ser agregados em quatro categorias principais: (1) sobre a base conceitual e definições de AE, (2) estudos sobre a transição, (3) estudos de agroecossistemas e (4) em biodiversidade.

Uma primeira especialidade em AE refere-se à análise do funcionamento dos agroecossistemas tradicionais, frequentemente centrados sob as práticas tradicionais $\mathrm{e}$ a gestão de variedades domesticadas, mas também têm destaque os estudos de pragas e doenças (AYRES, 1977; BRUSH et al., 1981; GLIESSMAN, 1983).

Outra abordagem importante dentro da agroecologia é a denominada etnoecologia. Esta disciplina é definida pelo estudo da sabedoria tradicional sobre a natureza. Considera a etnoecologia uma ciência transdisciplinar e de enfoque holístico. Neste sentido, deve compreender de maneira adequada os saberes tradicionais que se fundamentam numa complexa inter-relação entre as crenças, os conhecimentos e as práticas. As experiências tradicionais se baseiam nas experiências que se têm sobre o mundo, seus efeitos e significados e sua valorização de acordo com o contexto natural e cultural onde se encontram os grupos humanos (TOLEDO, 1992; TOLEDO; BARRERA BASSOLS, 2009). Enfatiza-se a dimensão geopolítica da agroecologia, a importância da reforma agrária e do fortalecimento das comunidades 
locais face ao processo de industrialização da agricultura (TOLEDO, 2010).

Altieri por sua vez, deriva em direção ao estudo de agroecossistemas, a partir dos estudos realizados sobre controle biológico. A AE, inicialmente focalizada sobre os sistemas tropicais, encontra-se hoje também desenvolvida nos sistemas temperados (KROMP, 1999; THIES; TSCHARNTKE, 1999).

As questões críticas levantadas em relação à $\mathrm{AO}$ também já tinham sido identificadas no final dos anos 1970 e centravam-se, sobretudo, nos seguintes aspectos: i) dificuldades relacionadas ao processo de conversão, devido à necessidade de uso intensivo de mão de obra (atribuída também à menor produtividade da mão de obra). Esta dificuldade é recolocada mais tarde em contextos associados à agricultura de base ecológica e orgânica; ii) a situação dos agricultores em conversão no geral estava associada à precariedade, devido à falta de mercados organizados e de reconhecimento formal de certificação (década de 1980); iii) bem como a inadequação do sistema dominante em absorver as alternativas, produzindo gargalos técnicos e, consequentemente, econômicos (YOUNGBERG, 1980).

Outra abordagem da $\mathrm{AE}$ concerne à análise crítica dos efeitos do desenvolvimento da revolução verde sobre o funcionamento dos agroecossistemas (GLIESSMAN et al., 1981; CONWAY; BARBIER, 1990). As ciências sociais são também mobilizadas para compreender os arranjos institucionais necessários para a ampliação da agricultura sustentável (CHAMBERS, 1983; CHAMBERS et al., 1989; CONWAY, 1997), em meados da década de 1990, estudando até hoje o papel do movimento social na transição agroecológica.

Pontos de convergência aparecem entre as áreas do conhecimento relativas à Agroecologia e à Agricultura Orgânica. A partir de 2000, em cada uma aparecem as especialidades relacionadas à biodiversidade e compartilham referências, principalmente com base em trabalho de ecologistas (CHIVERTON; SOTHERTON, 1991; KREBS et al., 1999; TOOLEY; BRUST, 2002; TSCHARNTKE et al., 2005). Estes estudos tinham como objetivo analisar o impacto diferenciado de sistemas de produção sobre a biodiversidade na produção agrícola. Essa última abordagem é evidente na AE (ALTIERI, 1999). Na literatura da AO, esses trabalhos têm sido igualmente relevantes.
A temática do solo, ancorada historicamente pela $\mathrm{AO}$, aparece hoje comumente nas análises dos dois estilos de agricultura (WEZEL; SOLDAT, 2009). Os autores destacam o forte crescimento das palavras-chave na produção científica em AE.

Recentemente, as duas áreas - $\mathrm{AO}$ e $\mathrm{AE}$ - compartilham inúmeras referências sobre a dinâmica do desenvolvimento institucional, particularmente na Europa (MICHELSEN, 2001; PADEL, 2001) e na América do Norte (BUCK et al., 1997), onde se desenvolveu o debate sobre a convencionalização da Agricultura Orgânica. (GUTHMAN, 2000; HALL; MOGYORODY, 2001).

Para Darnhofer et al. (2010), apesar de a AO possuir potencial para oferecer alimentos ecologicamente corretos e preservar o meio ambiente e as paisagens, alguns estudos têm mostrado que unidades de produção orgânicas, certificadas ou não, adotam práticas que não respeitam os princípios da agricultura orgânica. Esta tendência tem sido chamada de "convencionalização" da agricultura orgânica. Argumenta-se que para fortalecer a agricultura orgânica e potencializar seus benefícios teria que se avaliar a sua heterogeneidade e ir além da regulamentação. $\mathrm{O}$ argumento principal aponta para a necessidade de analisar empiricamente se a AO está cumprindo ou não com os princípios e valores defendidos pela IFOAM e se recomenda a adoção de indicadores que tenham capacidade de capturar o conjunto de causas e efeitos decorrentes das diferentes práticas adotadas.

Guthman (2000) já tinha avaliado as práticas de agricultores orgânicos na Califórnia, argumentando que em muitos casos essas práticas estão distantes dos princípios da Agroecologia. A autora afirma que existem algumas diferenças nas práticas entre produtores que produzem em sistemas orgânicos. Essas diferenças ocorrem mais em função das culturas cultivadas, da escala da produção e da disponibilidade de conhecimento e de tecnologia, e que depende fundamentalmente de como a produção orgânica é definida (concepção/princípios). Ela salienta a importância de normas orgânicas e regulamentos para moldar as práticas de produção orgânica. Outro aspecto apontado está relacionado à situação geográfica, às oportunidades ou restrições biofísicas, normas regionais e apoio institucional.

O debate da convencionalização da Agricultura Orgânica e o seu distanciamento dos princípios da AE e 
da AO (IFOAM, cf. DARNHOFER et al., 2010) foram apresentados no Brasil por Almeida e Abreu (2009). Os autores avaliam a aplicação de princípios agroecológicos empiricamente e levam em conta a configuração dominante do mercado de exportação e das estruturas produtivas e de mercado do Brasil. Esse trabalho mostra a importância da dimensão econômica e sua influência no processo de transição (conforme seção de Estudos de Casos).

Apoiados nos argumentos da convencionalização, foram também realizados estudos comparativos sobre as práticas de agricultores no Brasil, China e Egito (OELOFSE et al., 2011). Esses estudos avaliaram as mudanças nas práticas em unidades orgânicas certificadas na China, Brasil e Egito, sinalizando que a expansão global da agricultura orgânica tem indicado novos desafios, em particular se as práticas e a gestão das unidades produtivas orgânicas estão sujeitas à lei da convencionalização. $\mathrm{O}$ estudo toma partido da hipótese da convencionalização e analisa as práticas dos produtores orgânicos tendo em conta a aplicação ou não de princípios da $\mathrm{AO}$ e da AE. Os autores mostram que a adoção da Agricultura Orgânica tem induzido mudanças fundamentais nas práticas de manejo dos agricultores, embora essas práticas não correspondam aos princípios orgânicos definidos pela IFOAM.

Uma visão mais ampla de desenvolvimento rural e da relação com Agroecologia é também apontada de maneira tipificada pelos pesquisadores Hill (1985) e Rosset e Altieri (1997) e retomada em diversos trabalhos científicos relacionados ao tema (LAMINE; BELLON, 2009). Nesse contexto, o processo de transição agroecológica passa por diversas etapas internas e externas à unidade de produção. Considerando as condições internas ao agroecossistema, Gliesmann (2007) sugere que o processo de transição seja apresentado em quatro níveis: 1) aumento da eficiência de práticas convencionais, reduzindo o uso de insumos externos;

2) substituição de insumos e de práticas convencionais por práticas da agricultura de base ecológica;

3) redesenho do agroecossistema baseado em processos agroecológicos; e,

4) restabelecimento de uma ligação direta entre produtor e consumidor.

Esses níveis de transição não são lineares, herméticos ou determinados pelo tempo (mesmo se as normas da $\mathrm{AO}$ definem um horizonte temporal para a conversão). Por exemplo, um agricultor pode aumentar a eficiência de práticas orgânicas sem redesenhar o seu sistema produtivo. Mas, pode também trabalhar os níveis três e quatro em paralelo aos níveis básicos (LAMINE; BELLON, 2007). Assim, segundo o ponto de vista da $\mathrm{AE}$, é necessário pressupor um processo de evolução constante, o que evidencia uma fluidez e complementaridade entre $\mathrm{AO}$ e $\mathrm{AE}$, tendo a $\mathrm{AE}$ um papel paradigmático no desenvolvimento rural.

Hill (1985), Rosset e Altieri (1997), assim como Gliessman (2000), sugerem que, prevalecendo o paradigma de substituição de insumos no desenvolvimento da agricultura de base ecológica, problemas relacionados à crise socioeconômica e ecológica da agricultura convencional dificilmente serão resolvidos, já que uma simples substituição de insumos não resolverá o problema da monocultura por não valorizar a diversidade produtiva, a manutenção dos agricultores e suas famílias no campo, e também por não favorecer a geração e distribuição da renda gerada pela produção.

Tress (2001), ao estudar processos de conversão para a agricultura de base ecológica na Dinamarca, classificou a relação dos agricultores quanto à aplicação de princípios da agroecologia em dois polos extremos: o primeiro, antropocêntrico, consiste na busca da produtividade mediante o domínio direto da produção num quadro de referencial tecnológico em que a natureza recebe apenas um valor instrumental, e um segundo, de natureza ecológica, que busca a coexistência entre seres humanos e a natureza pela valorização de processos de regulação natural. $\mathrm{O}$ primeiro paradigma define a $\mathrm{AO}$ pela proibição de determinados insumos e pela prescrição de outros produtos por meio de uma lista autorizada de produtos naturais, definidos pelas normas da legislação de diferentes países (SYLVANDER et al., 2006; ALMEIDA; ABREU, 2009).

Recentemente, ainda, no Brasil, Primavesi (1997) e Feiden et al. (2002) classificaram a AO como "agricultura de produtos", pelas semelhanças com a agricultura convencional caracterizada por monocultivos e sistemas simplificados. Por outro lado, a AE foi definida por Primavesi (1997) e Feiden et al. (2002) como paradigma da “agricultura de processos" (ALMEIDA; ABREU, 2009).

$\mathrm{O}$ segundo paradigma da AE, que define os sistemas agroecológicos de uma maneira qualitativa e 
global com estímulo à rotação de culturas e ao contorno ecológico de problemas fitossanitários, estabelece uma construção ampla de sistemas de produção diversificados, com base nos modelos ecológicos nos quais as interações entre os componentes dos agroecossistemas asseguram propriedades de fertilidade, produtividade e resiliência (KALTOFT, 1999; VERHOOG et al., 2003; EMBRAPA, 2006; KALTOFT; RISGAARD, 2006), proporcionando serviços ambientais aos agricultores familiares. Nesse segundo paradigma, ocorre a participação de consumidores vigilantes sobre o processo de produção e o reconhecimento dos serviços ambientais.

O primeiro paradigma da agricultura de produtos leva à continuidade do processo de reconhecimento da existência de um mercado para produtos diferenciados e certificados. ${ }^{1}$ Esse pode ser também traduzido pela concentração do capital: baixa diversificação produtiva e produção em larga escala concentrada nas mãos de grandes produtores ou de empresas familiares, fato que não impede que ocorra também um mercado regional ou nacional. ${ }^{2}$

O paradigma da agricultura dos processos pode conduzir a uma participação significativa de pequenos agricultores e de seus familiares, garantindo a manutenção e o crescimento da renda familiar, bem como maior acesso à educação e treinamento técnico e maior diversificação produtiva, proporcionando segurança alimentar, possibilitando a evolução das relações comerciais e dos agroecossistemas.

\section{A controvérsia e as relações entre $A O$ e $A E$}

Alguns autores analisam a Agricultura Orgânica pensada em termos de sistemas de produção simplificados em oposição aos sistemas complexos da Agroecologia. Nesta oposição entre $\mathrm{AO}$ e $\mathrm{AE}$, a $\mathrm{AO}$ poderia assemelhar-se ao modelo da agricultura convencional. Essa percepção nega a diversidade interna dos sistemas produtivos que ocorrem empiricamente, inspirados mais ou menos pelos princípios da $\mathrm{AO}$ e da $\mathrm{AE}$. A visão baseada numa oposição está associada mais fortemente aos trabalhos de Miguel Altieri sobre o desenvolvimento da agricultura orgânica.

Canuto (2011, p. 129) também analisa cenários polarizados entre a agricultura orgânica associada ao processo industrial de substituição de insumos e a um tipo de mercado onde a apropriação do sobrepreço é evidente e a Agroecologia orientada para circuitos comerciais alternativos e de concepção ampliada para o social, o cultural e o político. Todavia, no Paraná, por exemplo, a venda de produtos orgânicos desde o início foi organizada de forma combinada entre vendas diretas, feiras e vendas em lojas e supermercados. $\mathrm{Na}$ França, a produção orgânica iniciou-se basicamente pela venda direta. Atualmente, segundo a Agence Bio, os supermercados vendem $47 \%$ da produção de orgânicos (AGENCE BIO, 2011) e a venda direta persiste (12\%), ou seja, ocorre também uma coexistência de circuitos curtos e longos de comercialização.

Entendemos ser prudente evitar simples oposições de paradigmas, distanciados da realidade socioeconômica e da produção familiar orgânica. É preciso levar em conta as heterogeneidades das formas produtivas orgânicas, suas lógicas de funcionamento, bem como as condições para produzir e os desafios colocados para os produtores orgânicos familiares. Naturalmente muitas unidades produtivas orgânicas funcionam tendo em conta a simples substituição de insumos e se inserem em mercados nacionais (supermercados) ou internacionais (BELLON; ABREU, 2005). Contudo, outras propriedades, tipicamente familiares, buscam mercados alternativos e vendas diretas para consumidores, com inserção de maneira combinada dentro de circuitos de comercialização, podendo ser o resultado de estratégias definidas em momentos específicos da trajetória de transição. É preciso realizar estudos empíricos para compreender os obstáculos e os limites que estão colocados no plano

\footnotetext{
${ }^{1}$ Ponto número 1 do Regulamento da CE 834/2007, na Europa.

${ }^{2}$ Em 2007, foram plantados no Brasil 888 mil hectares de culturas orgânicas certificadas (frutas, hortaliças, cereais, café, mel, leite, carnes, soja, palmito, açúcar e frango), posicionando o país no sexto lugar em área manejada, o que representa $0,25 \%$ da área agricultável total ocupada por 19.000 propriedades da agricultura de base ecológicas certificadas (WILLER; YUSSEFI, 2008; ABREU et al., 2009). O grupo social dessas propriedades é formado basicamente por agricultores familiares e por empresas que produzem para exportação (açúcar, suco de laranja, café, soja). 70\% dessa produção certificada se localiza nas regiões Sul e Sudeste do país (ABREU et al., 2009).
} 
socioeconômico e uma análise mais fina das práticas e usos dos princípios da Agroecologia. ${ }^{3}$

No contexto, principalmente, da literatura brasileira, deve-se considerar que a maioria dos autores rejeita o fato de a Agroecologia ser apresentada, muitas vezes, como uma forma alternativa de produção (CAPORAL; COSTABEBER, 2004). Outros defendem a Agroecologia a partir de uma posição crítica em relação à Agricultura Orgânica (ALTIERI; NICHOLLS, 2003; CANUTO, 2011). Entretanto, a legislação de sistemas de produção orgânicos é fruto de um processo de participação democrática e ação de diversos atores sociais representantes dos interesses da produção que favoreceu o reconhecimento das diversidades e estilos de produção ecológica (Lei Orgânica n. ${ }^{\circ}$ 10.831/2003; Diário Oficial da União de 24/12/2003; BERTONCELLO; BELLON, 2008; ABREU et al., 2009).

É importante destacar que a Lei da Produção Orgânica Brasileira, n. ${ }^{\circ}$ 10.831, conforme mencionado, teve sua formulação baseada no conceito de Agroecologia, que destaca diversos elementos integrantes da noção conceitual, tais como: a integridade cultural das comunidades rurais, a equidade social, a valorização econômica das produções familiares, além do respeito aos recursos naturais. Nesse sentido, sob o ponto de vista normativo, a noção de orgânico incorpora a de agroecológica e abrange um conjunto de estilos de agricultura: biodinâmica, orgânica, natural, permacultura, sistemas agroflorestais, regenerativo etc. e prevê três diferentes maneiras de garantir a qualidade dos seus produtos: a Certificação por Auditagem, os Sistemas Participativos de Garantia e o Controle Social para a Venda Direta sem Certificação; contrariamente ao Regulamento da Comunidade Europeia 834/2007 e às normas francesas, que foram influenciadas pela IFOAM ${ }^{4}$ (www.agencebio.org espace professionnels), onde todas as etapas, da produção à transformação, são objeto de controle dos organismos certificadores.

Na ocasião do Congresso da IFOAM em 2011 (Coreia), a IFOAM e a SOCLA assinaram um memorando de entendimento formalizando um quadro de relações entre instituições internacionais demonstrando, respectivamente, os vínculos entre AO e AE. Pode-se interpretar como uma articulação entre essas duas correntes, mas recentemente a IFOAM invocou o risco de sequestro da AO pela AE. Da mesma forma, um documento que foi bastante divulgado na mídia, o Relatório Especial sobre o Direito à Alimentação de Schutter (2010), não faz explicitamente referência à $\mathrm{AO}$. Assim os promotores da AO consideram que ela é um modelo implícito para apoiar as proposições atribuídas à AE (CAPLAT, 2012).

Embora as mudanças técnicas (dimensões agronômica e ambiental) sejam de grande importância, a transição agroecológica só poderá alcançar sua plenitude quando outras condições externas (dimensões social, econômica e política) à unidade de produção forem estabelecidas. Para Sevilla Guzman et al. (2006), a AE tem uma dimensão integral, em que as variáveis sociais ocupam uma dimensão muito relevante. Segundo a Embrapa (2006), há um conjunto de condições externas mais amplas a ser construído pela sociedade e pelo Estado para que a transição agroecológica possa se tornar realidade, tais como: expansão da consciência pública; organização dos mercados e o aporte de infraestruturas; mudanças institucionais na pesquisa, ensino e extensão; formulação de políticas públicas com enfoque em AE; e inovações referentes à legislação ambiental.

Outro aspecto fundamental é o reconhecimento de que a transição agroecológica se dará num prazo mais

\footnotetext{
${ }^{3}$ Uma pesquisa focada na situação empírica foi realizada no município de Ibiúna (SP), próximo da metrópole de São Paulo (num universo de 80 produtores orgânicos de hortaliças para supermercados e lojas da metrópole de São Paulo). Constatou-se que esses produtores familiares convivem com a falta ou deficiência de assistência técnica; a baixa qualidade da educação e falta de apoio institucional etc. A configuração social vinculada à precariedade do capital cultural e econômico do grupo os distancia de uma possível reconcepção dos agroecossistemas e de autonomia mais global (BERKER; ABREU, 2010). A reconcepção do sistema ou a substituição de insumos e aplicação minimalista das normas de produção podem estar vinculadas às dificuldades múltiplas do contexto social, mas também agronômico, com a falta de conhecimento e tecnologias disponíveis. Assim, essas dificuldades ou limites dificultam o processo de transição de uma forma de produção (agricultura convencional) a outra, que busca se aproximar dos princípios da (AE).

${ }^{4}$ A International Federation of Organic Agriculture Movements foi fundada no ano de 1972 em Versalhes, na França, por um grupo de personalidades da comunidade científica europeia ligada ao movimento da ecoagricultura e que criticavam o uso de produtos químicos e pesticidas nos sistemas de produção de alimentos. Desde então, o movimento foi ganhando força e a cada ano era maior o número de participantes nos congressos promovidos em torno do desenvolvimento da agricultura orgânica. A IFOAM caracteriza-se como a primeira instituição de interesse público a regulamentar um padrão internacional de certificação para a agricultura de base ecológica, ainda no ano de 1980 (ABREU et al., 2009).
} 
longo, se moldando às características de cada local, região ou território. Assim, as condições ecológicas, socioeconômicas e culturais delimitam os parâmetros de sustentabilidade, embora o foco seja sempre a construção de agriculturas que incorporem os princípios agroecológicos.

Estudos relacionados com integração ao mercado revelam a importância destes para compreender como afetam as formas de produção. Em estudo na região metropolitana de Curitiba com agricultura familiar de base ecológica, Darolt e Constanty (2008) mostraram que a opção por canais de venda direta e circuitos curtos repercute em sistemas de produção mais diversificados, independentes e com tendência a direcionar a propriedade para a multifuncionalidade. A diversificação, além de atender aos princípios da $\mathrm{AE}$, torna a propriedade mais atrativa aos consumidores. Todavia, o sistema de produção torna-se complexo e oneroso em mão de obra, diminuindo - em alguns casos - a eficiência técnica e econômica pelo aumento de custos de produção, mas maximizando as dimensões social e ambiental. Nesses casos, é comum também a opção de agricultores orgânicos pela certificação participativa. Verifica-se, nessa experiência, uma aproximação aos ideais da AE.

O estudo de Boeckmann e Caporal (2011), recentemente, buscou entender como os agricultores familiares que comercializam produtos agroecológicos em feiras se autodenominam orgânicos. Segundo os autores, os agricultores se denominam orgânicos apesar de adotarem os princípios da agroecologia, fato que denota os vários sentidos e usos das noções e ideias sobre AE e AO. Para esses autores, os agricultores devem ser esclarecidos do significado do termo orgânico e diferenciá-lo do termo agroecologia, expressando claramente as visões polarizadas do debate em questão. O debate sobre o significado da $\mathrm{AE}$ e da $\mathrm{AO}$ parece ter tomado consistência no Brasil, e o último Congresso Brasileiro de Agroecologia (Fortaleza, 2011) provavelmente contribuiu para uma organização das ideias sobre concepções e relações entre AO e AE.

No plano internacional, a controvérsia Agroecologia versus Agricultura Orgânica está igualmente presente Em alguns países europeus (Dinamarca), vários estudiosos mudaram de temática em AO para posições mais amplas acadêmicas em $\mathrm{AE}$, tanto na investigação quanto na educação. Análises comparativas devem ser conduzidas, valorizando trajetórias individuais na- cionais. Na França, a AE surgiu de forma harmoniosa e principalmente através de movimentos sociais. A agroecologia na França não é estabelecida como uma disciplina científica. No entanto, o Instituto Francês de Pesquisa Agrícola (INRA), a maior organização de pesquisa em agricultura na Europa, recentemente introduziu a AE como uma de suas prioridades (junto com a biologia preditiva). Entre as opções possíveis, a AE pode ser considerada como alternativa (i) combinando agronomia e ecologia (posição que aparentemente está sendo tomada oficialmente no INRA) ou (ii) como um projeto interdisciplinar, considerando as transições agrícolas em todas as suas dimensões (tecnológica, social, econômica). Outro centro de pesquisa francês mais diretamente orientado para cooperação internacional com países em desenvolvimento (CIRAD) enfatiza a versão tecnológica da AE com plantio direto e os métodos de proteção das culturas. Mais recentemente, a AE torna-se um "chavão" em muitas organizações públicas e privadas.

Do lado da sociedade civil e profissional, enquanto no Brasil, desde a década de 1990, a AE é um guia orientador das redes de agriculturas de base ecológica, na França, só recentemente é que algumas dessas redes começaram a se referir à $\mathrm{AE}$, a fim de reforçar a sua identidade sociopolítica em oposição às políticas de movimentos orgânicos.

\subsection{Estudos de caso e a relação entre $A O$ e $A E$}

O objetivo desta seção é apresentar os elementos que podem definir ou não um estilo de agricultura. Trata-se de dois estudos empíricos - o primeiro analisou as práticas de agricultores orgânicos em unidades de produção em relação aos princípios da $\mathrm{AO}$ e da $\mathrm{AE}$. No segundo, acompanhou-se a dinâmica de uma organização face à inter-relação e à evolução de princípios de ambas as concepções. No primeiro caso, se evidencia que as situações estruturais da produção podem gerar, ou não, possibilidades concretas da aplicação dos princípios da agroecologia. No segundo caso, é notório que essas práticas devem sempre ser interpretadas tendo em conta a dinâmica e as interações entre $\mathrm{AO}$ e $\mathrm{AE}$, onde a dimensão temporal, para além da ideia de conversão, é um elemento importante. 


\subsubsection{Um estudo de caso ilustrativo em transição entre $A O$ e AE em Itápolis/SP}

A pesquisa foi efetuada com 23 agricultores familiares, associados à Cooperativa dos Agropecuaristas Solidários de Itápolis/SP (COAGROSOL), já certificados pelo sistema de terceira parte orgânico (certificação em grupo de produtores) e alguns em fase de conversão. Representavam $70 \%$ dos agricultores certificados como orgânicos e pouco mais de $17,5 \%$ do quadro total de agricultores associados. Eram descendentes, em sua maioria, de imigrantes italianos. Possuíam, em média, 22,5 ha por unidade de produção. Em épocas específicas, contratavam serviços de terceiros para determinadas tarefas da produção, especificamente na época das colheitas. Algumas famílias cultivavam hortas, ervas naturais e criavam pequenos animais - galinhas, porcos, cabras para subsistência. O trabalho consistiu em identificar e caracterizar os sistemas de produção de um grupo de agricultores familiares por meio da análise do funcionamento e da gestão de seus respectivos sistemas produtivos, do ponto de vista dos princípios da $\mathrm{AE}$ e da AO. Portanto, verificou-se a aplicação de princípios da agricultura orgânica recomendados pela Internacional Federation for Organic Agriculture Movements (IFOAM) e os princípios da agroecologia recomendados pelo movimento ecológico sul-americano, com foco na agrobiodiversidade, na reciclagem de material e nos aspectos socioeconômicos do processo de conversão agroecológica (ALMEIDA; ABREU, 2009).

Uma das questões analisada foi a de verificar em que medida os agricultores certificados expressam diferentes princípios das agriculturas $\mathrm{AO}$ e AE segundo motivações ético-ecológicas ou segundo interesses produtivos e comerciais.

Os resultados do trabalho evidenciaram diferentes paradigmas de relação produtiva com os recursos naturais. Os agricultores mais experimentados conduziram suas respectivas atividades produtivas mais próximas do paradigma da agricultura de processos, ao utilizarem diferentes aportes dos modos de agricultura de base ecológica. O outro grupo de agricultores aplicou princípios produtivos oriundos de uma visão mais mercantilista, característica do paradigma da agricultura de produtos, na expectativa de aumentar as receitas obtidas com a comercialização dos produtos orgânicos certificados. Dessa maneira, foi possível verificar, no grupo de agricultores certificados como orgânicos ou em fase de conversão/ transição, a convivência de distintas formas de relação produtiva com os agroecossistemas.

Os cooperados que aplicaram os princípios da $\mathrm{AE}$ e da $\mathrm{AO}$ em suas atividades e práticas agroecológicas interagiam de forma equilibrada com a natureza e compreendiam melhor os ciclos naturais dos agroecossistemas, denotando melhorias na gestão financeira da unidade de produção, o aumento da agrobiodiversidade produtiva $\mathrm{e}$ a reciclagem de material.

A análise sobre a aplicação dos princípios da agricultura de base ecológica permitiu avaliar a existência de uma diferenciação produtiva e constatar que a crescente diversificação da produção assegurava melhorias na remuneração econômica das atividades, promovendo também a transformação da paisagem e o redesenho dos agroecossistemas.

Todos os agricultores entrevistados praticavam a substituição de insumos nas práticas. Mas, conforme o aumento do conhecimento técnico e dos objetivos ecossociais dos agricultores e de suas famílias, outras práticas produtivas eram então utilizadas, além da substituição de insumos. Verificou-se que, como consequência da adoção de princípios da $\mathrm{AE}$ e da $\mathrm{AO}$, quanto maior a integração de práticas dos diferentes estilos de agricultura, mais diversificados foram os agroecossistemas e, consequentemente, havia aumento dos patamares de integração natural com base no paradigma da agricultura de processos.

Concluiu-se que o estabelecimento de relações econômicas entre a cooperativa e uma entidade internacional de comércio tem estimulado o aumento expressivo na diversificação produtiva e na aplicação de princípios da $\mathrm{AO}$ e da $\mathrm{AE}$, bem como proporcionado uma visível mudança de atitude quanto à exploração dos recursos naturais da região, localizada em uma das bacias hidrográficas mais degradadas do Estado de São Paulo, em razão da poluição por agroquímicos e pesticidas e da ausência de matas nativas (ALMEIDA; ABREU, 2009).

Descobriu-se, além disso, que o papel da assistência técnica da cooperativa foi fundamental nos trabalhos de construção das práticas e no seu acompanhamento, 
o que permitiu a evolução dos seus conhecimentos. A experiência social positiva que os agricultores certificados têm experimentado nos últimos anos embasou-se em atitudes de iniciativa coletiva deste grupo, proporcionadas pela união entre os agricultores familiares da cooperativa. A presença do Estado no desenvolvimento da agricultura familiar de base ecológica da região restringiu-se às poucas linhas de crédito para a agricultura orgânica e para o custeio das safras. Não havia projetos de assistência técnica vinculados às esferas do poder público. Portanto, situações empíricas onde se estudam a natureza das práticas dos agricultores e suas condições sociais e econômicas devem ser focalizadas para compreender em que medida os princípios da $\mathrm{AO}$ e da AE estão sendo incluídos de forma integrada e quais os elementos da transição interna ou externa que podem estar impedindo o avanço do processo.

\subsubsection{O caso da AOPA - Paraná}

Na época de sua fundação, em 1995, a AOPA foi batizada de Associação de Agricultura Orgânica do Paraná e tinha cerca de 250 famílias associadas, organizadas em 17 grupos de agricultores familiares, situados na Região Metropolitana de Curitiba e na Região Sul do Estado do Paraná. A AOPA trabalhava no sentido de garantir para os agricultores um processo de capacitação para o sistema de produção de base ecológica com orientação técnica, política e organizacional e, além disso, buscava assegurar a comercialização dos produtos, garantindo sua procedência para o mercado consumidor.

No seu início, a AOPA trabalhou num processo de comercialização de produtos orgânicos associando circuitos curtos e circuitos longos. Com o passar do tempo, as vendas se concentraram, sobretudo, em circuitos longos junto aos supermercados da metrópole de Curitiba. Nesse período, a dependência dos supermercados evidenciou a fragilidade de se trabalhar com poucos canais de comercialização e num sistema similar à lógica convencional.

A partir do ano 2003, houve uma mudança na forma de atuar, com uma alteração de nome da associação para Associação para o Desenvolvimento da Agroecologia (AOPA) e um trabalho associado à Rede Ecovida de
Agroecologia, onde se privilegiou a certificação participativa, os circuitos curtos de comercialização em feiras de produtores, mercado institucional e alimentação escolar.

$\mathrm{O}$ estudo mostrou que os agricultores de base ecológica que optam pela venda indireta (integrados com empresas e circuitos longos) normalmente se especializam em poucos produtos, são mais dependentes trabalhando com poucos canais de comercialização e optando pela certificação por auditoria. Nesse caso, os sistemas de produção são simplificados. A lógica de produção se aproxima muito de um sistema convencional, com maior eficiência técnica e econômica, porém menor eficiência ecológica e social. Essas características mostram uma fase de transição que chega apenas ao nível de substituição de insumos, atendendo às normas da $\mathrm{AO}$, mas ainda a avançar para atender aos preceitos da AE.

A história da AOPA mostra claramente uma fluidez na utilização dos termos $\mathrm{AO}$ e $\mathrm{AE}$ entre o final dos anos de 1990 e a primeira década do novo século. Atualmente, percebe-se uma aproximação entre os termos $\mathrm{AO}$ e AE, visível em nível nacional com a recente Política Nacional de Agroecologia e Sistemas Orgânicos de Produção de 2012. A mesma tendência pode ser visualizada nos Estados do Brasil, mostrando a importância de fortalecer o movimento das agriculturas que se diferenciam do modelo convencional.

\subsection{A teoria e a prática na relação Agroecologia e Agricultura Orgânica}

Segundo os estudos de caso, o conhecimento dos métodos e dos processos produtivos está sob controle e domínio dos agricultores e nesse sentido estes, cada vez mais esclarecidos, podem caminhar no sentido de buscar uma melhor eficácia dos insumos utilizados, ou ir mais longe, estabelecendo o redesenho dos agroecossistemas, os quais podem ser compreendidos como uma evolução conjunta e harmônica das estruturas de exploração produtiva e da paisagem, associadas à diminuição da utilização de insumos provindos de fora dos agroecossistemas produtivos. Dessa forma, as unidades produtivas diversificadas promovem transformações na paisagem. Além disso, uma menor dependência econômica do mercado seria uma das consequências relevantes desse processo. 
Segundo essa concepção, baseada no conceito da Agroecologia, é preciso ir além da aplicação dos princípios da eficiência do uso de insumos e da substituição. Como mencionado anteriormente, foi observado empiricamente que em algumas situações os agricultores partem diretamente para a substituição de insumos, sem passar pela aplicação do princípio do uso eficiente dos insumos químicos. Além disto, se ocorrer o redesenho efetivo da unidade de produção, isto se traduz por modificações no uso do solo e de outras atividades (associação policultivo - vegetal e animal), inclusive na relação com o mercado.

Assim, em diferentes territórios pode ser observada uma fluidez entre $\mathrm{AO}$ e $\mathrm{AE}$, ou seja, as fronteiras conceituais e conteúdos estão em plena evolução.

Analisando sob a perspectiva da transição, conforme sugerido por Gliesmann (2007), indicado em seção anterior, verificamos que em termos de pesquisa agrícola considera-se que houve avanços no trabalho de transição do nível um para o nível dois, com a redução do uso de insumos, controle e manejo integrado, técnicas de cultivo mínimo do solo, previsão da ocorrência de pragas e doenças, controle biológico, variedades adaptadas, rotação de culturas, cultivos em faixas ou intercalados, entre outras inovações. Entretanto, esses dois primeiros níveis envolvem apenas mudanças internas do sistema, enquanto que o terceiro e quarto níveis implicam mudanças mais profundas da estrutura e função do sistema e do seu entorno.

Embora no Brasil não se tenha uma estatística sobre esses níveis, estima-se que a maior parte das propriedades certificadas como AO tenham chegado ao nível de transição 2. Em relação aos níveis 3 e 4, o processo está apenas começando. O redesenho ainda é um desafio para a $\mathrm{AO}$ e refere-se à construção de agroecossistemas diversificados, reforçando os princípios ecológicos. Da mesma forma, a ligação direta entre quem produz e quem consome envolverá uma mudança de atitudes e de valores da sociedade e, portanto, uma mudança paradigmática.

\section{Conclus̃̃es}

A discussão sobre a relação entre agricultura AE se situa no campo de disputas políticas e define princípios, critérios de pertencimento e de legitimidade científica.
Neste sentido, o conceito de Pierre Bourdieu contribuiu para clarificar esse debate, uma vez que a Agroecologia parece ter potencial para modificar, transformar e enriquecer o conceito atual de Agricultura Orgânica. De um lado, a Agroecologia parece avançar sobre o campo da Agricultura Orgânica; de outro, demarca mais claramente os princípios e práticas desse estilo de agricultura.

A AO tem um papel importante como agricultura de base ecológica, devido à sua história (quase um século), aos seus princípios para a ação (conjunto de regras) e práticas codificadas (regulamentos), aos seus controles e certificação, à sua crescente importância econômica e à sua identificação pelos consumidores. A AE tende a reforçar a identidade como um projeto orientado para a ação interdisciplinar, com as suas especialidades oferecendo um conjunto de contribuições importantes para a diversificação de cultivos, serviços para a biodiversidade, justiça social e soberania alimentar. Isso implica: (i) aprofundar as relações já construídas com os movimentos sociais, e (ii) buscar convergências benéficas através de uma fértil relação entre $\mathrm{AO}$ e $\mathrm{AE}$. A este respeito, os esforços de investigação contribuem para compreender o redesenho de agroecossistemas sustentáveis. AO e AE têm um papel importante e expressam novas tendências das políticas da multifuncionalidade da agricultura e aproximação entre produtores e consumidores.

O processo histórico que levou ao que se entende atualmente por $\mathrm{AO}$ e $\mathrm{AE}$ passou por diversas mudanças e atualmente se verifica, no Brasil, uma aproximação entre as diversas concepções do movimento alternativo à agricultura convencional. Essa aproximação de caráter pragmático é realizada na prática por agricultores e conduz à emergência de uma forma híbrida de fazer agricultura, cujos elementos resultam da convergência para AO e AE. Nasce assim outra forma de fazer agricultura, resultante de um hibridismo AO x AE. Nesse sentido, nossas análises nos levam a concluir que as interações dessas duas formas mais comuns de fazer agricultura alternativa no Brasil (AO e AE) promovem a transição para uma agricultura tida como sustentável ou ecológica, segundo os preceitos definidos por Gliesmann (2009). Essa tendência que se verifica, na realidade, não significa, no entanto, a anulação ou exclusão de um ou outro modelo. Pelo contrário, tanto a Agricultura Orgânica como a Agroecologia avançam seguindo cada qual seu próprio 
movimento. De um lado, a Agricultura Orgânica avança nos âmbitos da agricultura empresarial e patronal, de outro, a Agroecologia amplia espaços junto a agricultores familiares e camponeses, impulsionada pelos movimentos sociais e políticas públicas, essas mesmo que ainda tímidas. Além disso, deve-se ressaltar o caráter político e social que reveste a concepção da Agroecologia, uma vez que relacionado a processos de cunho emancipatório de categorias sociais, como camponeses excluídos do processo de modernização da agricultura.

\section{Referências}

ABREU, L. S.; LAMINE, C.; BELLON, S. Trajetórias da Agroecologia no Brasil: entre movimentos sociais, redes científicas e políticas públicas. In: CONGRESSO BRASILEIRO DE AGROECOLOGIA, 6., CONGRESSO LATINO-AMERICANO DE AGROECOLOGIA, 2., 2009. Anais... Curitiba, 2009.

; BRANDENBURG, A.; BELLON, S.; MAZAROTTO, S. D. V. A. Agroecologia, movimento social, ciência, práticas e políticas públicas: uma abordagem comparativa. In: CONGRESSO BRASILEIRO DE AGROECOLOGIA, 7., CONGRESSO LATINO-AMERICANO DE AGROECOLOGIA, 3., 2011. Anais... Fortaleza, 2011.

AGENCE BIO. L'agriculture biologique française: les chiffres clés. Paris, 2011.

ALMEIDA, G.; ABREU, L. S. Estratégias produtivas e aplicação de princípios da Agroecologia. Revista de Economia Agrícola, v. 56, n. 1, p. 37-53, 2009.

ALTIERI, M. A. Agroecology: the scientific basis of alternative agriculture. Boulder, CO: Westview Press, 1987.

Agroecologia: as bases científicas da agricultura alternativa. Trad. Patrícia Vaz. Rio de Janeiro: PTA/FASE, 1989.

El "estado del arte" de la agroecología y su contribución al desarrollo rural en América Latina. In: CADENAS, M. A. (Org.). Agricultura y desarrollo sostenible. Madrid: MAPA, 1995.

The ecological role of biodiversity in agroecosystems. Agriculture Ecosystems \& Environment, v. 74, n. 1-3, p. 19-31, 1999.

; NICHOLLS, C. I. Agroecology rescuing organic agriculture from a specialized industrial model of production and distribution. Ecology and Farming, v. 34, p. 24-26, 2003.
Reforça-se também a premissa de que a análise da $\mathrm{AO}$ e da $\mathrm{AE}$ não deve ser tratada de forma polarizada, visto que ambas têm um peso social, ambiental e econômico importante, principalmente para a agricultura familiar.

Considerando que nos debates acadêmicos praticamente não se tem dado atenção para o estudo das relações aqui identificadas, este trabalho traz contribuições que precisam ser aprofundadas em outros casos, visando alimentar o debate científico e as contribuições para a formulação de políticas públicas.

AYRES, P. The growth of Arrhenatherum elatius var bulbosum (Willd.) Spenn. in spring barley, as influenced by cultivation. Weed Research, v. 17, n. 6, p. 423-428, 1977.

BELLON, S.; ABREU, L. S. Formas sociais de desenvolvimento da horticultura orgânica familiar em áreas de cinturão verde do território de Ibiúna, Estado de São Paulo. Cadernos de Ciência \& Tecnologia, v. 22, n. 2, p. 381-398, 2005.

; LAMINE, C. Enjeux et débats actuels sur la conversion à l'AB. In: LAMINE, C.; BELLON, S. (Orgs.). Transitions vers l'agriculture biologique: pratiques et accompagnements pour des systèmes innovants. Paris: Quae/Educagri, 2009.

; OLLIVIER, G.; ABREU, L. S. The relationships between organic farming and agroecology. In: ISOFAR - INTERNATIONAL SOCIETY OF ORGANIC AGRICULTURE RESEARCH, 2011. Anais... Gyeonggi Paldang (Coreia), 2011.

BERKER, M.; ABREU, L. S. Trajetórias de transição dos produtores de base ecológica de Ibiúna/sp e indicadores sociais de sustentabilidade. Sociedade e Desenvolvimento Rural, v. 4, n. 1, 2010. Disponível em: <http://www.inagrodf.com.br/ revista/index.php/SDR/article/viewPDFInterstitial/79/74>. Acesso em: 03/2012.

BERTONCELLO, B.; BELLON, S. Construction and implementation of an organic agriculture legislation: the brazilian case. In: IFOAM ORGANIC WORLD CONGRESS, 2008. Anais... Modena (Italy), 2008.

BOECKMANN, M. S.; CAPORAL, F. R. Agroecologia: uma ciência para além da substituição de insumos. Cadernos de Agroecologia, v. 6, n. 2, 2011.

BOURDIEU, P. Homo academicus. Madrid: Siglo XX1, 2008. 
BOURN, D.; PRESCOTT, J. A comparison of the nutritional value, sensory qualities, and food safety of organically and conventionally produced foods. Critical Reviews in Food Science and Nutrition, v. 42, n. 1, p. 1-34, 2002.

BRANDENBURG, A. Os novos atores da reconstrução do ambiente rural no Brasil: o movimento ecológico na agricultura. Estudos Sociedade Agricultura, v. 19, n. 1, 2011.

BRUSH, S. B.; CARNEY, H. J.; HUMÁN, Z. Dynamics of Andean potato agriculture. Economic Botany, v. 35, n. 1, p. 70-88, 1981.

BUCK, D.; GETZ, C.; GUTHMAN, J. From farm to table: the organic vegetable commodity chain of Northern California. Sociologia Ruralis, v. 37, n. 1, p. 3-20, 1997.

BUTTEL, F. H. Envisioning the Future Development of Farming in USA: agroecology between extinction and multifunctionality? New Directions in Agroecology Research and Education, 2003.

BYÉ, P.; SCHMIDT, V. B.; SCHMIDT, W. Transferência de dispositivos de reconhecimento da agricultura orgânica e apropriação local: uma análise sobre a Rede Ecovida. Desenvolvimento e Meio Ambiente, v. 6, p. 81-93, 2002.

CANUTO, J. C. Invesgación en agroecología: instituciones, métodos y escenarios futuros. In: MORALES HERNÁNDEZ, J. (Org.). La agroecologia: en la construcción de alternativas hacia la sustentabilidad rural. México: Siglo XXI Editores/Instituto Tecnológico y de Estudios Superiores de Occidente, 2011.

CAPLAT, J. L'agriculture biologique pour nourrir l'humanité: démonstration. Arles: Actes Sud, 2012.

CAPORAL, F. R.; COSTABEBER, J. A. Agroecologia: Aproximando conceitos com a noção de sustentabilidade. In: RUSCHEINSKY, A. (Org.). Sustentabilidade: uma paixão em movimento. Porto Alegre: Sulina, 2004.

CHAMBERS, R. Rural development: putting the last first. London: Longman, 1983.

; PACEY, A.; THRUPP, L. A. Farmer first: farmer innovation and agricultural research. London: Intermediate Technology Publications, 1989.

CHIVERTON, P.; SOTHERTON, N. The effects of beneficial arthropods of the exclusion of herbicides from cereal crop edges. Journal of Applied Ecology, p. 1027-1039, 1991.

CONWAY, G. R. The doubly Green Revolution: food for all in the twenty-first century. London: Penguin Books, 1997.

; BARBIER, E. B. After the green revolution. Sustainable agriculture for development. London: Earthscan, 1990.
DALGAARD, T.; HUTCHINGS, N.; PORTER, J. Agroecology, scaling and interdisciplinarity. Agriculture, Ecosystems \& Environment, v. 100, p. 39-51, 2003.

DARNHOFER, I.; LINDENTHAL, T.; BARTEL-KRATOCHVIL, R.; ZOLLITSCH, W. Conventionalisation of organic farming practices: from structural criteria towards an assessment based on organic principles. A review. Agronomy for Sustainable Development, v. 30, p. 67-81, 2010.

DAROLT, M. R.; CONSTANTY, H. Producers and Consumers Relationship Strategies in the Organic Market in Brazil. In: ISOFAR SCIENTIFIC CONFERENCE, 2., 2008. Proceedings... Modena (Italy), 2008.

DE SCHUTTER, O. Agroécologie et droit à l'alimentation. ONU. Rapport du Rapporteur spécial sur le droit à l'alimentation.ONU. Rapport présenté à la 16ème session du Conseil des droits de l'homme de l'ONU, 2010. Disponível em: <http://www.srfood.org/images/stories/pdf/ officialreports/20110308_a-hrc-16-49_agroecology_fr.pdf $>$.

EMBRAPA. Marco referencial em Agroecologia. Brasília, DF: Empresa Brasileira de Pesquisa Agropecuária, 2006.

FEIDEN, A.; LOPES DE ALMEIDA, D.; VITOI, V.; LINHARES DE ASSIS, R. Processo de conversão de sistemas de produção convencionais para sistemas de produção orgânicos. Cadernos de Ciência e Tecnologia, v. 19, n. 2, p. 179-204, 2002.

FRANCIS, C. Education in Organic Farming and Food Systems. In: FRANCIS, C. (Org.). Organic farming: the ecological system. ASA/CSSA/SSSA, 2009.

; LIEBLEIN, G.; GLIESSMAN, S.; BRELAND, T. A.; CREAMER, N.; HARWOOD, R.; SALOMONSSON, L.; HELENIUS, J.; RICKERL, D.; SALVADOR, R.; WIEDENHOEFT, M.; SIMMONS, S.; ALLEN, P.; ALTIERI, M.; FLORA, C.; POINCELOT, R. Agroecology: The ecology of food systems. Journal of Sustainable Agriculture, v. 22, n. 3, p. 99-118, 2003.

GLIESSMAN, S. R. Allelopathic interactions in crop-weed mixtures. Journal of Chemical Ecology, v. 9, n. 8, p. 991-999, 1983.

. Agroecology: researching the basis for sustainable

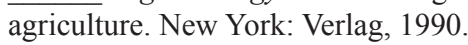

Agroecologia: processos ecológicos em agricultura sustentável. Porto Alegre: UFRGS, 2000.

.Agroecology: the ecology of sustainable food systems. New York: CRC Press, Taylor \& Francis, 2007.

Agroecologia: processos ecológicos em agricultura sustentável. 4. ed. Porto Alegre: Ed. Universidade/UFRGS, 2009. 
; GARCIA, R.; AMADOR, M. The ecological basis for the application of traditional agricultural technology in the management of tropical agro-ecosystems. Agro-Ecosystems, v. 7, n. 3, p. 173-185, 1981.

GUTHMAN, J. Raising organic: An agro-ecological assessment of grower practices in California. Agriculture and Human Values, v. 17, p. 257-266, 2000.

GUZMÁN CASADO, G.; GONZÁLEZ DE MOLINA, M.; GUZMÁN, E. Introducción a la agroecología como desarrollo rural sostenible. Madrid: Mundi-Prensa, 2000.

HALL, A.; MOGYORODY, V. Organic farmers in Ontario: An examination of the conventionalization argument. Sociologia Ruralis, v. 41, n. 4, p. 399-322, 2001.

HILL, S. B. Redesigning the food system for sustainability. Alternatives Journal - Canadian Environmental Magazine, v. 3/4, p. 32-36, 1985.

IFOAM. The infoam norms for organic production and processing; version 2005. Disponível em: <http://www.ifoam. org/about_ifoam/standards/norms/norm_documents_library/ Norms_ENGV4_20090113.pdf>.

KALTOFT, P. Values about nature in organic farming practice and knowledge. Journal of the European Society for Rural Sociology, v. 39, n. 1, p. 39-53, 1999.

; RISGAARD, M. Has organic farming modernized itself out of business? Reverting to conventional methods in Denmark. In: HOLT, G.; REED, M. (Orgs.). Sociological perspectives of organic agriculture: from pioneer to policy. Wallingford: CABI, 2006.

KREBS, J. R.; WILSON, J. D.; BRADBURY, R. B.; SIRIWARDENA, G. M. The second silent spring? Nature, p. 611-612, 1999.

KROMP, B. Carabid beetles in sustainable agriculture: a review on pest control efficacy, cultivation impacts and enhancement. Agriculture, Ecosystems \& Environment, v. 74, n. 1-3, p. 187228, 1999.

LAMARCHE, H. (Org.) A agricultura familiar: comparação internacional. Campinas: Editora da UNICAMP, 1993.

LAMINE, C.; ABREU, L. S. Compared trajectories of agroecology in Brazil and France: the role of scientists and social movements. In: ESRS CONGRESS, BOOK OF ABSTRACTS, 2009. Anais... Vaasa (Finland), 2009.

; BELLON, S. La conversion au bio, un objet multidimensionnel aucroisement des sciences agronomiques et des sciences sociales. Avignon (France): INRA, 2007.
; BELLON, S. (Orgs). Transitions vers l'agriculture biologique: pratiques et accompagnements pour des systèmes innovants. Paris: Editions Quae; Educagri, 2009.

LEFF, E. Saber ambiental: sustentabilidade, racionalidade, complexidade, poder. 6. ed. Petrópolis: Vozes, 2008.

LOCKERETZ, W.; SHEARER, G.; KOHL, D. H. Organic Farming in the Corn Belt. Science, v. 211, n. 4482, p. 540$547,1981$.

MAGNUSSON, M. K.; ARVOLA, A.; HURSTI, U. K. K.; ÅBERG, L.; SJÖDÉN, P. O. Choice of organic foods is related to perceived consequences for human health and to environmentally friendly behaviour. Appetite, v. 40, n. 2, p. 109-117, 2003.

MICHELSEN, J. Recent development and political acceptance of organic farming in Europe. Sociologia Ruralis, v. 41, n. 1, p. 3-20, 2001 .

NELSON, E.; SCOTT, S.; CUKIER, J.; LEIVA, A. Institutionalizing agroecology: successes and challenges in Cuba. Agriculture and Human Values, v. 26, p. 233-243, 2009.

ODUM, E. P. The strategy of ecosystem development. Scien$c e$, n. 164, p. 262-270, 1969. Disponível em: <http://phobos. ramapo.edu/ vasishth/Odum-Strategy_of_Ecosystem_Development.pdf $>$.

; BARRETT, G. W. Fundamentals of Ecology. Fifth Edition. Belmont, California: Thomson Brooks/Cole, 2005. 598 p.

OELOFSE, M.; HOGH-JENSEN, H.; ABREU, L. S.; ALMEIDA, G. F. D.; EL-ARABY, A.; HUI, Q. Y.; SULTAN, T.; NEERGAARD, A. D. Organic farm conventionalisation and farmer practices in China, Brazil and Egypt. Agronomy for Sustainable Development, v. 31, n. 4, p. 589-698, 2011.

OLLIVIER, G.; BELLON, S.; PENVERN, S. Thematic and citation structure dynamics of Organic Food \& Farming research. In: ISOFAR SCIENTIFIC CONFERENCE, 3., at the IFOAM ORGANIC WORLD CONGRESS, 17., 2011. Anais... Gyeonggi Paldang, Republic of Korea, 2011.

PADEL, S. Conversion to organic farming: a typical example of the diffusion of an innovation? Sociologia Ruralis, v. 41, n. 1, p. 40-61, 2001.

PIMENTEL, D.; HURD, L. E.; BELLOTTI, A. C.; FORSTER, M. J.; OKA, I. N.; SHOLES, O. D.; WHITMAN, R. J. Food production and energy crisis. Science, v. 182, n. 4111, p. $443-$ 449, 1973.

PRIMAVESI, A. M. Agroecologia: ecosfera, tecnosfera e agricultura. São Paulo: Nobel, 1997. 
REBELATTO DOS SANTOS, L. C. Certificação participativa em rede: um processo de certificação adequado à agricultura familiar agroecológica no Sul do Brasil, 2005. Disponível em: $<$ http://www.agroecologia.inf.br/biblioteca/Certificacao\%20 em\%20Rede\%20-\%20Luiz\%20Rebelatto\%20Santos.pdf $>$.

REIJNTJES, C.; HAVERKORT, B.; WATERS-BAYER, A. Farming for the future: an introduction to low-external-input and sustainable agriculture. London: Macmillan Press, 1992.

ROSSET, P.; ALTIERI, M. A. Agroecology versus input substitution: A fundamental contradiction of sustainable agriculture. Society and Natural Resources, v. 10, n. 3, p. 283-295, 1997.

SARANDON , S. J. Educación y formación en agroecología: una necesidad impostergable para un desarrollo rural sustentable. In: CONGRESSO BRASILEIRO DE AGROECOLOGIA, 2.; CONGRESSO LATINO-AMERICANO DE AGROECOLOGIA, Curitiba, 2009. Anais... Curitiba, 2009.

SCHIFFERSTEIN, H. N. J.; OUDE OPHUIS, P. A. M. Health-related determinants of organic food consumption in the Netherlands. Food quality and Preference, v. 9, n. 3, p. 119-133, 1998.

SEVILLA GUZMÁN, E.; OTTMANN, G.; GONZÁLEZ DE MOLINA, M. Los marcos conceptuales de la Agroecología. In: MARCO, A. B.; FIGUEIREDO, J. R. T. D. L. (Orgs.). Agroecologia: conceitos e experiências. Recife: Bagaço, 2006.

SYLVANDER, B.; BELLON, S.; BENOIT, M. Facing the organic reality: the diversity of development models and their consequences on research policies. In: JOINT ORGANIC CONGRESS, 2006. Anais... Odense (Denmark), 2006.

THIES, C.; TSCHARNTKE, T. Landscape structure and biological control in agroecosystems. Science, v. 285, n. 5429, p. 893, 1999.

TOLEDO, V. M. What is ethnoecology? Origins, scop and implications of a rising discipline. Etnological, v. 1, n. 1, p. 5-21, 1992.

. As experiências agroecológicas no México. Uma visão geopolítica. Agriculturas: Experiências em Agroecologia, AS-PTA, v. 7, n. 1, p. 40-45, 2010.

; BARRERA BASSOLS, N. A etnologia: uma ciência pós-normal que estuda as sabedorias tradicionais. Desenvolvimento e Meio Ambiente, Curitiba: Editora UFPR, n. 20, p. 31-45, jul./dez. 2009.
TOOLEY, J.; BRUST, G. Weed seed predation by carabid beetles. The agroecology of carabid beetles, p. 215-229, 2002.

TRESS, B. Converting to organic agriculture-Danish farmer's views and motivations. Norwegian Journal of Geography, v. 101, p. 131-143, 2001.

TSCHARNTKE, T.; KLEIN, A. M.; KRUESS, A.; STEFFANDEWENTER, I.; THIES, C. Landscape perspectives on agricultural intensification and biodiversity-ecosystem service management. Ecology Letters, v. 8, n. 8, p. 857-874, 2005.

VAN DEN AKKER, J. Convergence entre les systèmes participatifs de garantie et les systèmes de contrôle interne dans un projet pilote européen d'IFOAM. Innovations Agronomiques, v. 4, p. 441-446, 2009.

VAN DER PLOEG, J. D. Sete teses sobre a agricultura camponesa. Revistas Agriculturas: Experiências em Agroecologia, AS-PTA, v. 6, 2009.

VANCE, E. D.; BROOKES, P. C.; JENKINSON, D. S. An extraction method for measuring soil microbial biomass $\mathrm{C}$. Soil Biology and Biochemistry, v. 19, n. 6, p. 703-707, 1987.

VERHOOG, H.; MATZE, M.; VAN BUEREN LAMMERTS, E.; BAARS, T. The role of the concept of the natural (naturalness) in organic farming. Journal of Agricultural and Environmental Ethics, v. 16, n. 1, p. 29-49, 2003.

WEZEL, A.; BELLON, S.; DORÉ, T.; FRANCIS, C.; VALLOD, D.; DAVID, C. Agroecology as a science, a movement and a practice. A review. Agronomy for Sustainable Development, v. 29, n. 4, p. 503-515, 2009.

; SOLDAT, V. A quantitative and qualitative historical analysis of the scientific discipline of agroecology. International Journal of Agricultural Sustainability, v. 7, n. 1, p. 3-18, 2009.

WILLER, H.; YUSSEFI, M. The world of organic agriculture: statistics and emerging trends. In: IFOAM ORGANIC WORLD CONGRESS, 2008. Anais... Modena (Italy), 2008.

WOESE, K.; LANGE, D.; BOESS, C.; BOGL, K. W. A comparison of organically and conventionally grown foods-results of a review of the relevant literature. Journal of the Science of Food and Agriculture, v. 74, n. 3, 1997.

YOUNGBERG, G. Organic farming: a look at opportunities and obstacles. Journal of Soil and Water Conservation, v. 35, p. 254-263, 1980.

Recebido em 7 de maio de 2012. Aceito em 4 de setembro de 2012. Publicado em dezembro de 2012. 